\title{
Purification of cadmium by selective volatilization in vacuum in presence of oxide phase on its melt
}

\author{
N R MUNIRATHNAM*, K SRINIVASA RAO and T L PRAKASH \\ Centre for Materials for Electronics Technology (C- MET), IDA Phase- III, Cherlapally, HCL (P.O), \\ Hyderabad 500 051, India
}

MS received 23 December 2010; revised 14 August 2011

\begin{abstract}
Purification of cadmium in the presence of a thin $(\sim 0.001 \mathrm{~mm})$ oxide layer on the surface of the molten metal was carried out using a simple system designed and fabricated locally. The analytical results revealed that the distillation through oxide layer gave better separation for $\mathrm{Co}, \mathrm{Ni}, \mathrm{Cu}, \mathrm{Zn}, \mathrm{Ag}, \mathrm{Sn}, \mathrm{Hg}$ and $\mathrm{Tl}$, when compared to the distillation without oxide layer. This was attributed due to the impurity metal oxide phases formation on the surface of the molten metal. The influence of oxygen flow time on the distillation rate of cadmium was established. There was no excess oxygen $(O)$ retained in the distillate after two consecutive vacuum distillations through oxide route. The experiments were conducted at the level of nearly $1.5 \mathrm{~kg}$ a batch to study the impurities behaviour due to upscaling. The detailed chemical analysis of 58 impurity elements in $\mathrm{Cd}$ in presence and absence of oxide layer was carried out by glow discharge mass spectrometry (GDMS).
\end{abstract}

Keywords. High purity; cadmium; selective evaporation; oxide layer; glow discharge mass spectrometry.

\section{Introduction}

The extreme purities in individual metals is motivated by the theoretical limitations of separating the impurities and practical importance of determining the intrinsic physical properties. One part of impurity in the million of a matrix metal can significantly influence the physical properties (Kinchin et al 1981; Capper 1982; Murarka et al 1993; Keksi 2002). Preparation of high purity metals demands a combination of different chemical and physical refining methods (Safarzadeh et al 2007). As the degree of refinement increases to higher levels, purification methods are predominately based on physical processes like vacuum distillation, crystallization, diffusion, electro-migration, etc, (Singh et al 1968). The distillation at batch scale requires considerable control of experimental parameters, which can play an important role in the separation of $\mathrm{ppb} / \mathrm{ppt}$ level impurities.

The basis for vacuum distillation technique is separation of impurities during evaporation followed by condensation of a relatively pure part owing to the difference in vapour pressure and controlled by separation coefficient of impurities in the vapour phase. Comparison of experimental data on impurity distribution coefficient in melt-solid and separation coefficients in melt-vapour phases (Devyatikn and Eliev 1982), suggest that the latter method is preferred due to simple equipment and reduced process time. Under volatilization conditions in vacuum, the most difficult impurity to separate is $\mathrm{Zn}$ in $\mathrm{Cd}$ due to its separation coefficient of two

\footnotetext{
*Author for correspondence (rathnam1960@gmail.com)
}

(Kovalevski et al 1996). It was reported that by adding metal oxide phases, a considerable change in the physico-chemical behaviour of several impurities can occur during purification (Kovalevski et al 1996). The main principal is the oxidized part of cadmium $(\mathrm{CdO})$ which extracts impurity from the melt as an oxide $\mathrm{A}_{\mathrm{r}} \mathrm{O}_{\mathrm{s}}$, where " $\mathrm{A}$ " represents impurity element, $r$ and $s$ are the respective valences. The impurity distribution between the phases is assumed to be homogeneous in composition and determined by thermodynamic equilibrium. At equilibrium the reaction looks like $r \mathrm{~A}+s \mathrm{CdO} \leftrightarrow$ $\mathrm{A}_{\mathrm{r}} \mathrm{O}_{\mathrm{s}}+{ }_{s \mathrm{Cd}}$, at a partial pressure $P_{i}^{0}$ and temperature of evaporation, $T$ (K) (Ali et al 2004).

The purification work as was reported by Kovalevski et al (1996), was carried out using 1.5 to $1.8 \mathrm{~kg}$ of input material and distillation was carried out in a quartz tube. Normally these kind of experiments have to be conducted at kilogram level in order to harvest the $\mathrm{R} \& \mathrm{D}$ into technology and later on upscale to a required batch scale of production. The grams scale also will give similar results, because, the separation of impurities depends on partial pressures of individual metal impurities with respect to parent matrix element. In this case the matrix element is cadmium. However, the equipments for purification used by Kovaleski et al (1996) were quartz tubes and graphite boats. Also, the impurities analysed shows higher detection limits (percentages), probably due to the higher limit of quantification (LOQ) of the analytical equipments used.

In order to adopt this technique into practice, one has to demonstrate the purification process, with suitable materials of construction of the equipment, because, in our experience, quartz tube breaks with $\mathrm{CdO}$ and $\mathrm{SiO}_{2}$ (quartz) reaction during 
cooling and heating cycles due to thermal expansion differences. Hence, a simple design using stainless steel retort and graphite crucible for collection was adopted.

This piece of work deals with the simple equipment constructed using locally available materials for purification which circumvents the use of expensive and imported quartz tubes. All the results were analysed using glow discharge mass spectrometry (GDMS) available at the National Research Council (NRC), Canada. GDMS technique is the most suitable analytical tool for the quantification of parts per billion (ppb)/parts per trillion (ppt) level impurities in high purity material matrices and compound semiconductors, because, it adopts no chemicals in sample preparation. In view of this, we have separately given these results and compared the extent of separation of impurities with and without oxide layer on cadmium melt.

The purity achieved by distillation through oxide phase at a batch scale and detailed impurity analysis by GDMS has not been reported in the literature. Variation in the mass to be purified is expected to change the purification process parameters considerably. We report in this paper a comparative study on the purification of cadmium through normal vacuum distillation and distillation through oxide layer and detailed impurity analysis using GDMS for nearly 58 impurity elements in Cd matrix.

\section{Experimental}

The details of vacuum distillation assembly are given in figure 1. The metal evaporator and collector system essentially consisted of two cylindrical crucibles made up of isostatic fine grain high density graphite (R-7340) inverted over

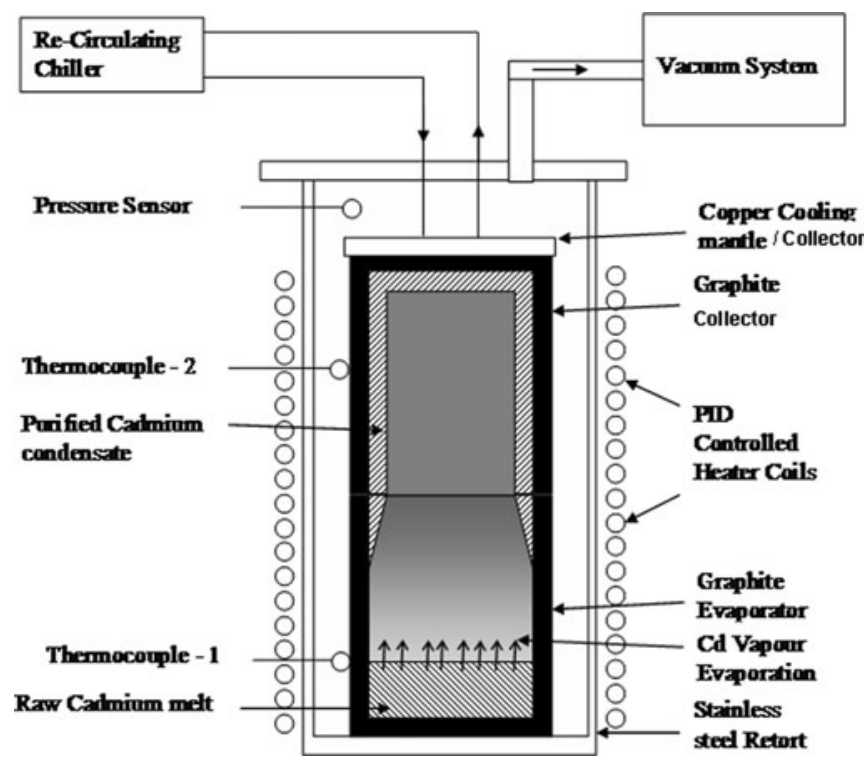

Figure 1. Schematic diagram showing components distillation assembly. one on the other. A copper cooling jacket was placed on the top of the crucible which acted as a condenser. A cup shaped graphite filter ( $3 \Phi$ filter holes) had dimensions of $60-100$ $(\mathrm{OD}) \times 150(\mathrm{H}) \times 10(\mathrm{~T}) \Phi$, where 60 and 100 were bottom and top OD, respectively and $\mathrm{H}$ and $\mathrm{T}$ were height and thickness, respectively. Similarly, the collector had the dimensions of 100-120 (OD) $\times 200(\mathrm{H}) \times 8(\mathrm{~T}) \Phi$ and evaporator had the dimensions of $100-120(\mathrm{OD}) \times 310(\mathrm{H}) \times 8(\mathrm{~T}) \Phi$. The entire assembly was placed in a stainless steel (SS316) retort connected to a vacuum system. This SS retort was placed in a heating furnace with a provision to control the temperature within $\pm 5^{\circ} \mathrm{C}$. The system was dynamically maintained at a vacuum of nearly $2 \times 10^{-5}$ torr before starting the melt evaporation and nearly $2 \times 10^{-4}$ torr during the distillation process.

\subsection{Vacuum distillation of cadmium}

The commercial grade cadmium (99.9 at.\%) was filtered to remove excess oxides by melting in the filter assembly under a dynamic vacuum. The darkish brown coloured residue indicated the presence of excess copper and other metal oxides. Elemental analysis of the residue using inductively coupled plasma optical spectrometry (ICPOES) showed the accumulation of $\mathrm{Pb}$ and $\mathrm{Cu}$ to the extent of 230 and $210 \mathrm{ppm}$, respectively.

Nearly $5 \mathrm{~kg}$ of filtered cadmium was loaded into the bottom graphite crucible. After fixing the top crucible and cooling jacket, the temperature was increased to $200^{\circ} \mathrm{C}$ to remove any moisture under a dynamic vacuum of nearly $10^{-5}$ torr. Subsequently, the high vapour pressure impurities were removed at a temperature $50^{\circ} \mathrm{C}$ below the distillation temperature, under the same pressure conditions. After 15 min of time, the collection chamber was replaced with a freshly cleaned third graphite crucible and the experiment was repeated at a temperature $70^{\circ} \mathrm{C}$ above the melting point of cadmium. After $2 \mathrm{~h}$ of distillation, the furnace was cooled to room temperature $(R T)$. The SS retort was opened after flushing with inert Ar-gas for a couple of times to remove any trapped gases. Finally, the distillate was removed by sliding down the crucible. The samples were cut from the hat at different places for analysis. This hat shaped cadmium was subsequently cut into pieces of nearly 1 inch size and loaded into a freshly cleaned graphite crucible. In other words, the purified distillate from the first stage was used as an input material for the second stage. The second stage vacuum distillation was repeated by adopting similar experimental procedure as that of first stage.

\subsection{Vacuum distillation of cadmium through oxide layer}

Similarly, in a separate experiment, about $0.9 \mathrm{~kg}$ of filtered cadmium was oxidized with a predetermined oxygen flow rate of nearly 40 SCCM for 30 min using mass flow meter (Bromkhost high-tech type E-7600-AAA). The duration of time was selected based on series of distillation experiments 
with variable oxide formation time. The thickness of the $\mathrm{CdO}$ layer was estimated microscopically after taking a transverse section of the top portion of the ingot, polishing the piece and taking the image. The thickness was measured to be around $0.001 \mathrm{~mm}$. The distillation experiment was repeated for various times in the same manner as described above.

\subsection{Sample preparation and analysis}

High pure cadmium sample of $0.5 \mathrm{~g}$ each was dissolved in a $5 \mathrm{ml}$ sub-boiled nitric acid in a $25 \mathrm{ml}$ teflon beaker. The solution was fed to inductively coupled plasma emission spectrometer (ICP-OES), and inductively coupled plasma mass spectrometer (ICPMS). The grease, if any, during handling of the cadmium sample was cleansed by shaking in $1 \%$ subboiling nitric acid for $1 \mathrm{~min}$. The matix separation of cadmium was also carried out on some batches for the analysis on ICPMS. The results analysed using ICPOES were taken only to establish the effectiveness of purification process for specific impurities in case of oxide layer formation on cadmium. However, detailed results on cadmium purification on similar experiments were published elsewhere from this laboratory (Munirathnam et al 2005; Ali et al 2006, 2007). The cadmium distillates from the 1 st and 2 nd stages of vacuum distillation in presence and absence of oxide layer were analysed by GDMS at the National Research council (NRC), Canada.

\section{Results and discussion}

The distillation rate of cadmium in $\mathrm{g} / \mathrm{h}$ was plotted against the oxide layer formation time (min) and is shown in figure 2 . These experimental results of distilled cadmium revealed that the rate of distillation as a function of distillation time decreased exponentially with the increase in oxide concentration on the cadmium melt surface, at least up to $40 \mathrm{~min}$. The weight of input material quantity, oxide layer forma-

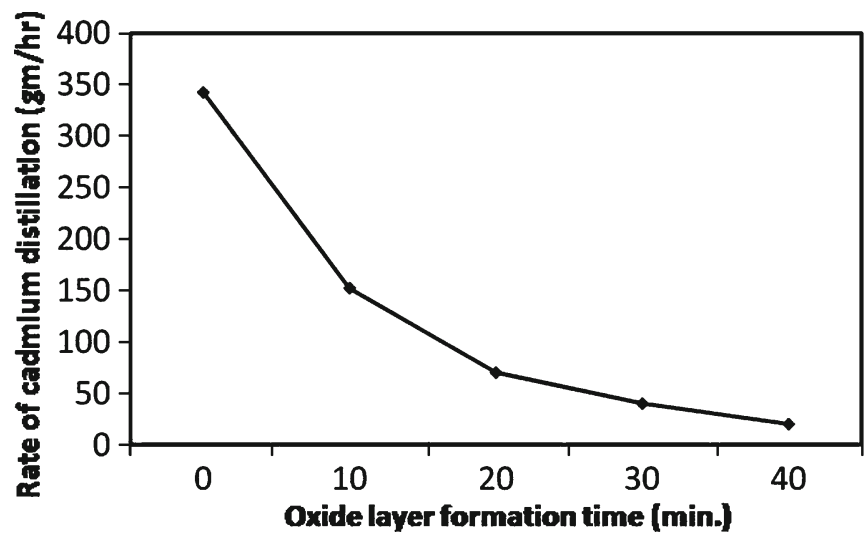

Figure 2. Variation of cadmium distillation rate $(\mathrm{g} / \mathrm{h})$ with oxide layer formation time ( $\mathrm{min})$.
Table 1. Rate of distillation of cadmium as a function of oxygen flow rate onto $\mathrm{Cd}$ melt.

\begin{tabular}{lccc}
\hline S1. no. & $\begin{array}{c}\text { Input } \\
\text { cadmium } \\
(\mathrm{g})\end{array}$ & $\begin{array}{c}\text { Oxygen layer } \\
\text { formation time } \\
(\mathrm{min})\end{array}$ & $\begin{array}{c}\text { Rate of distillation } \\
\text { of cadmium } \\
(\mathrm{g} / \mathrm{h})\end{array}$ \\
\hline 1 & 845 & With out oxide layer & 342 \\
2 & 847 & 10 & 152 \\
3 & 885 & 20 & 70 \\
4 & 880 & 30 & 40 \\
5 & 860 & 40 & 20 \\
\hline
\end{tabular}

tion time and rate of distillation $(\mathrm{g} / \mathrm{h})$ are shown in table 1 . The oxide film thickness was calculated to be nearly equal to $0.001 \mathrm{~mm}$ at $30 \mathrm{~min}$ of oxygen flow @ 40 SCCM. Zinc impurity analysis on ICPOES revealed that its concentration in Cd distillate decreased exponentially from $600 \mathrm{ppm}$ to 290 for $10 \mathrm{~min}$ of oxide layer formation and then it almost stabilized after $30 \mathrm{~min}$ of oxide layer formation. In other words, further increase in oxide layer thickness beyond $0.001 \mathrm{~mm}$ had no significant change in the separation of $\mathrm{Zn}$ from $\mathrm{Cd}$. This was ascribed due to the formation of thermo-dynamical equilibrium for the separation of $\mathrm{Zn}$ in $\mathrm{Cd}$.

Based on the behaviour of impurities during cadmium purification, it was expected that the impurities such as $\mathrm{Cu}$, $\mathrm{Ag}, \mathrm{Au}, \mathrm{Pb}, \mathrm{S}, \mathrm{Bi}, \mathrm{Co}, \mathrm{Ni}$, Pt should remain in the evaporator in the form of solution in $\mathrm{Cd}$ while $\mathrm{Li}, \mathrm{Na}, \mathrm{Be}, \mathrm{Mg}, \mathrm{Ca}$, $\mathrm{Zn}, \mathrm{Sr}, \mathrm{Ba}, \mathrm{B}, \mathrm{Al}, \mathrm{Sc}, \mathrm{Ga}, \mathrm{Y}, \mathrm{In}, \mathrm{La}, \mathrm{Si}$, Ti, Ge, Zr, Sn, Hf, V, $\mathrm{Nd}, \mathrm{Ta}, \mathrm{Cr}, \mathrm{Mo}, \mathrm{W}, \mathrm{Mn}, \mathrm{Fe}$ should remain in the oxide phase (Keksi 2002). This implies that Zn impurity was expected to remain in the oxide phase. Detailed GDMS analytical results of 58 impurity elements from the first and second distillations through oxide phase from is shown in table 2.

\subsection{Behaviour of $C, N$ and $O$ impurities}

The carbon $(\mathrm{C})$, nitrogen $(\mathrm{N})$ and oxygen $(\mathrm{O})$ impurities in input cadmium were 900, 110 and $4300 \mathrm{ppm}$, respectively. These were increased to 4000, 2800 and $7600 \mathrm{ppm}$ after first distillation. This was attributed primarily due to the unforeseen contamination from the adsorbed surface oxides dissolved into the melt. After subsequent 2 nd vacuum distillation, $\mathrm{C}, \mathrm{N}$ and $\mathrm{O}$ in $\mathrm{Cd}$ were reduced to 2500,640 and $2200 \mathrm{ppm}$, respectively. On the other hand, after oxidation and 1st distillation, $\mathrm{C}, \mathrm{N}$ and $\mathrm{O}$ impurities in $\mathrm{Cd}$ increased to 4200, 760 and 99000 ppm and after subsequent 2 nd vacuum distillation, they were reduced to 1700,690 and $2800 \mathrm{ppm}$, respectively. Although the content of $\mathrm{O}$ was higher after the 1 st distillation due to the oxide layer formation, the $\mathrm{Cd}$ distillate after 2 nd distillation contained relatively comparable contents of $\mathrm{C}, \mathrm{N}$ and $\mathrm{O}$ in $\mathrm{Cd}$. This indicated that by distilling through oxide phase there was no difficulty of excess oxygen after two consecutive distillations. In addition, appreciable gain in the separation of metallic impurities would be an added advantage. 
Table 2. GDMS analytical results of vacuum distilled cadmium. Cd-RM is input material, Cd-1 is after 1 st vacuum distillation, Cd-2 is after 2 nd vacuum distillation, Cd-O-1 is after 1 st vacuum distillation in the presence of oxide layer and Cd-O-2 is after $2 \mathrm{nd}$ vacuum distillation in the presence of oxide layer.

\begin{tabular}{|c|c|c|c|c|c|c|c|c|c|c|c|}
\hline \multirow[b]{2}{*}{ Impurity } & \multirow[b]{2}{*}{ Cd-RM } & \multirow[b]{2}{*}{$\mathrm{Cd}-1$} & \multirow[b]{2}{*}{$\mathrm{Cd}-2$} & \multirow[b]{2}{*}{ Cd-O-1 } & \multicolumn{2}{|c|}{ (mass ppb) } & \multirow[b]{2}{*}{ Cd-RM } & \multirow[b]{2}{*}{$\mathrm{Cd}-1$} & \multirow[b]{2}{*}{$\mathrm{Cd}-2$} & \multirow[b]{2}{*}{ Cd-O-1 } & \multirow[b]{2}{*}{$\mathrm{Cd}-\mathrm{O}-2$} \\
\hline & & & & & $\mathrm{Cd}-\mathrm{O}-2$ & Impurity & & & & & \\
\hline $\mathrm{Li}$ & $<7$ & $<5$ & $<11$ & $<9$ & $<7$ & $\mathrm{Br}$ & $<8$ & $<8$ & $<15$ & $<6$ & $<7$ \\
\hline $\mathrm{Be}$ & $<2$ & $<1$ & $<2$ & $<1$ & $<1$ & $\mathrm{Rb}$ & $<0.4$ & $<0.3$ & $<1$ & $<0.4$ & $<0.4$ \\
\hline B & $<2$ & 5 & 11 & $<2$ & 2 & $\mathrm{Sr}$ & $<0.4$ & $<0.2$ & $<1$ & $<0.2$ & $<0.3$ \\
\hline $\mathrm{C}$ & 900 & 4000 & 2500 & 4200 & 1700 & $\mathrm{Y}$ & $<0.3$ & $<0.2$ & $<0.5$ & $<0.3$ & $<0.3$ \\
\hline $\mathrm{N}$ & 110 & 2800 & 640 & 760 & 690 & $\mathrm{Zr}$ & $<0.3$ & $<0.3$ & $<0.5$ & $<0.5$ & $<0.3$ \\
\hline $\mathrm{O}$ & 4300 & 7600 & 2200 & 99000 & 2800 & $\mathrm{Nb}$ & $<0.4$ & $<0.3$ & $<1$ & $<0.4$ & $<0.4$ \\
\hline $\mathrm{F}$ & $<4$ & $<1$ & $<5$ & $<1$ & $<2$ & Mo & $<1$ & $<1$ & $<2$ & $<0.9$ & $<0.9$ \\
\hline $\mathrm{Na}$ & 49 & 7 & 97 & 20 & $<3$ & $\mathrm{Pd}$ & NA & NA & NA & NA & NA \\
\hline $\mathrm{Mg}$ & $<3$ & $<1$ & $<3$ & $<2$ & $<2$ & $\mathrm{Ag}$ & 7400 & $<40$ & $<25$ & $<25$ & $<8$ \\
\hline $\mathrm{Al}$ & $<2$ & $<2$ & $<2$ & 5 & $<1$ & $\mathrm{Cd}$ & Matrix & Matrix & Matrix & Matrix & Matrix \\
\hline $\mathrm{Si}$ & 4 & 14 & 45 & 19 & 7 & In & $<20$ & $<45$ & $<45$ & $<120$ & $<25$ \\
\hline $\mathrm{P}$ & $<1$ & $<1$ & $<2$ & $<1$ & $<1$ & $\mathrm{Sn}$ & 57 & $<15$ & $<25$ & $<7$ & $<8$ \\
\hline S & 87 & 5 & $<5$ & 5 & $<2$ & $\mathrm{Sb}$ & 290 & $<2$ & $<2$ & $<1$ & $<0.9$ \\
\hline $\mathrm{Cl}$ & 5 & 26 & 67 & 44 & 8 & $\mathrm{Te}$ & $<35$ & $<90$ & $<30$ & $<85$ & $<55$ \\
\hline K & $<1$ & $<2$ & $<10$ & $<4$ & $<1$ & I & $<20$ & $<15$ & $<130$ & $<75$ & $<75$ \\
\hline $\mathrm{Ca}$ & $<10$ & $<8$ & $<40$ & $<10$ & $<10$ & Cs & $<3$ & $<3$ & $<10$ & $<9$ & $<6$ \\
\hline $\mathrm{Sc}$ & $<0.6$ & $<0.4$ & $<0.9$ & $<0.5$ & $<0.5$ & $\mathrm{Ba}$ & $<8$ & $<5$ & $<30$ & $<8$ & $<12$ \\
\hline $\mathrm{Ti}$ & $<0.3$ & $<0.9$ & $<0.5$ & $<0.3$ & $<0.3$ & $\mathrm{La}$ & $<3$ & $<65$ & $<15$ & $<25$ & $<20$ \\
\hline V & $<0.2$ & $<0.2$ & $<0.3$ & $<0.2$ & $<0.2$ & $\mathrm{Ce}$ & $<6$ & $<11$ & $<25$ & $<45$ & $<30$ \\
\hline $\mathrm{Cr}$ & $<1$ & $<0.8$ & $<3$ & $<1$ & $<1$ & $\mathrm{Hf}$ & $<0.3$ & $<0.3$ & $<0.5$ & $<0.2$ & $<0.3$ \\
\hline $\mathrm{Mn}$ & $<20$ & $<20$ & $<20$ & $<20$ & $<20$ & $\mathrm{Ta}$ & NA & NA & NA & NA & NA \\
\hline $\mathrm{Fe}$ & $<15$ & $<15$ & $<15$ & $<15$ & $<15$ & W & 10 & 15 & $<1$ & $<0.8$ & $<0.6$ \\
\hline Co & 1000 & $<0.3$ & $<0.7$ & $<0.2$ & $<0.2$ & $\mathrm{Pt}$ & $<0.6$ & $<0.5$ & $<1$ & $<0.5$ & $<0.6$ \\
\hline $\mathrm{Ni}$ & 27000 & 10 & 20 & $<3$ & $<2$ & $\mathrm{Au}$ & $<5$ & $<5$ & $<5$ & $<5$ & $<5$ \\
\hline $\mathrm{Cu}$ & 570000 & 190 & 330 & 33 & $<2$ & $\mathrm{Hg}$ & 110 & 40 & 32 & $<10$ & $<5$ \\
\hline $\mathrm{Zn}$ & 78 & 57 & 130 & $<4$ & $<4$ & $\mathrm{Tl}$ & 9800 & 6 & 18 & 67 & 0.8 \\
\hline Ga & $<1$ & $<0.9$ & $<2$ & $<1$ & $<1$ & $\mathrm{~Pb}$ & 480000 & 130 & 110 & 36 & $<0.7$ \\
\hline $\mathrm{Ge}$ & $<3$ & $<2$ & $<4$ & $<2$ & $<2$ & $\mathrm{Bi}$ & 19 & $<0.4$ & $<0.7$ & $<0.4$ & $<0.4$ \\
\hline As & $<10$ & $<10$ & $<10$ & $<10$ & $<10$ & $\mathrm{Th}$ & $<0.6$ & $<0.5$ & $<0.9$ & $<0.9$ & $<0.8$ \\
\hline $\mathrm{Se}$ & $<15$ & $<25$ & $<25$ & $<6$ & $<25$ & $\mathrm{U}$ & $<0.09$ & $<0.06$ & $<0.1$ & $<0.08$ & $<0.08$ \\
\hline
\end{tabular}

$\mathrm{NA}=$ Not analysed

\subsection{Separation of metallic impurities}

Cadmium purification results with and without oxide layer showed substantial reduction of zinc impurity in cadmium distilled with oxide layer. On the other hand, without the oxide layer, the $\mathrm{Zn}$ in $\mathrm{Cd}$ was reduced from $2 \mathrm{ppm}$ to $0.6 \mathrm{ppm}$ after first distillation and then to $0.4 \mathrm{ppm}$ after subsequent second distillation (Ali et al 2004). In the present work, $\mathrm{Zn}$ in $\mathrm{Cd}$ was reduced from 78 to $57 \mathrm{ppb}$ after first distillation in the process where there is no oxide layer and to $<4 \mathrm{ppb}$ after first distillation through oxide phase. The basic reaction mechanism was $r \mathrm{~A}+s \mathrm{CdO} \leftrightarrow \mathrm{A}_{\mathrm{r}} \mathrm{O}_{\mathrm{s}}+s \mathrm{Cd}$, where ' $r$ ' is the number of impurity atoms of ' $\mathrm{A}$ ' to be separated and ' $s$ ' the number of $\mathrm{CdO}$ molecules or cadmium atoms. During the process of purification, the most difficult impurity to remove is zinc, because of its distribution coefficient in melt-vapour systems, which is 2 (Kovalevski et al 1996). It was also demonstrated that the behaviour of the physico-chemical system used in purification by adding new phases changes the behaviour of several impurities. Hence, in this case by introducing $\mathrm{CdO}$ into the system essentially influences the results of purification of impurities with greater affinity to oxygen than cadmium. This class of impurities includes zinc in addition to others (Shelpakova et al 1993). The other impurities like Mg, $\mathrm{Al}, \mathrm{Fe}, \mathrm{Cu}, \mathrm{Pb}, \mathrm{Ag}, \mathrm{Co}, \mathrm{Ni}, \mathrm{Sb}, \mathrm{Bi}$ have also been reduced by nearly two orders. The results tabulated in table 2 also indicated that the degree of separation of $\mathrm{Ni}, \mathrm{Cu}, \mathrm{Zn}, \mathrm{Ag}, \mathrm{Sn}, \mathrm{Hg}$ and $\mathrm{Tl}$ were higher during distillation through oxide layer, when compared to without oxide layer. It was also observed during experimentation that the rate of distillation decreased from $350-400 \mathrm{~g} / \mathrm{h}$ (without oxide film) to $125-150 \mathrm{~g} / \mathrm{h}$ (with oxide film). This indicated a mesh like behaviour of oxide layer on the cadmium melt by retaining the metal oxides and allowing the metal to evaporate. 


\section{Conclusions}

The following are the major conclusions:

(I) The experimental system designed and fabricated with all indigenous components can distill cadmium up to $6 \mathrm{~N}$ (99.999 at\%.) purity at batch scale.

(II) The zinc in cadmium reduced drastically from $78 \mathrm{ppb}$ to $<0.4 \mathrm{ppb}$ in the presence of oxide layer, which other wise was difficult to remove due to separation coefficient in melt vapour system close to 2 .

(III) The impurities like $\mathrm{C}, \mathrm{N}$ and $\mathrm{O}$ reduced considerably during second distillation in the presence of its oxides.

(IV) Significant reduction in $\mathrm{Co}, \mathrm{Ni}, \mathrm{Cu}, \mathrm{Sn}, \mathrm{Sb}, \mathrm{Hg}, \mathrm{Tl}$ and $\mathrm{Pb}$ in $\mathrm{Cd}$ was observed due to the presence of small amount of metal-oxides on the molten surface during vacuum distillation.

(V) The results can be effectively used to enhance the design for higher capacities of cadmium distillation using novel purification of cadmium metal through oxide phase and the purification of cadmium at a higher batch scale without sacrificing the purity required.

\section{Acknowledgement}

This work was carried out mainly due to the financial support from the Department of Science and Technology (DST),
New Delhi, vide grant No. SR/S3/ME/ 90/ 2003- SERCENGG.

\section{References}

Ali S T, Munirathnam N R, Sudheer C, Reddy R C and Prakash T L 2004 Mater. Lett. 581638

Ali S T, Munirathnam N R, Sudheer C, Reddy R C, Reddy M R P and Prakash T L 2007 Mater. Lett. 611512

Ali S T, Reddy R C, Munirathnam N R, Sudheer C, Anil G and Prakash T L 2006 Sep. Purif. Technol. 52288

Capper P 1982 J. Cryst. Growth 57280

Devyatikn G G and Eliev Yu E 1982 Introduction to theory of deep purification of substances (Moscow: Nauka), p. 320

Keksi T 2002 Eur. Integr. Stud. Miskolc. 1109

Kinchin M A, Willardson R K and Beer A C (eds) 1981 Semiconductor and semimetals (New York: Academic Press), Vol. 18, pp. 313-20

Kovalevski S V, Kosyakov V I and Shelpakova I R 1996 J. Cryst. Growth 167208

Munirathnam N R, Prasad D S, Rao J V, Sudheer Ch and Prakash T L 2005 Bull. Mater. Sci. 28209

Murarka S P, Gutmann R J, Kaloyeros A E and Lanford W A 1993 Thin Solid Films 236257

Safarzadeh M S, Bafghi M S, Moradkhani D and Ilkhchi M O 2007 Min. Engg. 20211

Shelpakova I R, Kosyakov V I and Chanisheva T A 1993 J. Anal. Chem. 48610

Singh A J, Mathur B S, Suryanarayana P and Tripathi S N 1968 Proc. symp. non-ferrous metals (Jamshedpur: NML), Vol. 3, pp. 82-5 